\title{
EL CARTULARIO TOLEDO, BIBLIOTECA CAPITULAR DE TOLEDO, 42-20 (1190) Y SU APORTACIÓN A LA HISTORIA INSTITUCIONAL DE LA SEDE TOLEDANA*
}

\section{THE TOLEDO CARTULARY, CAPITULARY LIBRARY OF TOLEDO, 42-20 (1190) AND ITS CONTRIBUTION TO THE HISTORY OF TOLEDO CATHEDRAL}

\author{
RUTH Miguel FRANCO \\ Universitat de les Illes Balears \\ http://orcid.org/0000-0002-0748-5763
}

\begin{abstract}
Resumen: El cartulario Toledo, Biblioteca Capitular de Toledo, 42-40 (1190), además de ser el más antiguo de los producidos en la catedral de Toledo, puede considerarse un ejemplo de cartulariocrónica. No solo recoge documentación real, eclesiástica y privada relativa a esta institución, sino que también contextualiza las piezas copiadas, bien en relación a acontecimientos históricos, bien con respecto a la propia catedral y a otros de sus bienes o documentos. El propósito de este artículo es analizar la construcción de este cartulario y los mecanismos que utiliza para convertir los documentos individuales en una narración de la historia institucional de la catedral de Toledo, centrada principalmente en los privilegios de la mesa capitular.
\end{abstract}

Palabras Clave: Toledo; cabildo; cartulario; crónica histórica; documentación.

\begin{abstract}
The Toledo cartulary, Capitulary Library of Toledo, 42-40 (1190), is the oldest cartulary produced in Toledo Cathedral. It may also be considered an example of a cartulary-chronicle, as this volume not only includes royal, ecclesiastical and private documents relative to the institution (?), but it also includes some pieces of writing that contextualize the copied documents by relating them either to historical events, or to the $\mathrm{Ca}$ thedral itself and to other assets or documents. The aim of this article is to analyze the construction of this cartulary and the mechanisms that it uses to transform individual documents into an account of the institutional history of Toledo Cathedral, focusing on the privileges of the mensa capitularis.
\end{abstract}

Keywords: Toledo; chapter; cartulary; historical chronicle; documents.

\footnotetext{
* Este trabajo se inscribe en los siguientes proyectos de investigación: Los textos latinos en la Hispania medieval (ss. V-XV): cambios, interferencias e influencias III (JCyL, SA215U14), financiado por la Junta de Castilla y León; Edición electrónica integral de las Biblias españolas medievales y renacentistas, financiado con una ayuda de la Fundación BBVA a Equipos de Investigación Científica 2016 / Humanidades Digitales.
} 


\section{SUMARIO}

1. Introducción. Cartularios e historia.- 2. El cartulario BCT 42-20 en la producción catedralicia.- 3. La construcción del cartulario crónica.- 3.1. El autor del cartulario.3.2. Del documento al cartulario.- 3.3. La organización de los materiales.- 4. Conclusiones.- 5. Bibliografía.

\section{INTRODUCCIÓN. CARTULARIOS E HISTORIA ${ }^{1}$}

Numerosos trabajos estudian cómo las comunidades humanas de cualquier tipo, religiosas, familiares, con vínculos sociales o geográficos, han producido narrativa histórica, entendiendo "narrativa histórica" en un sentido amplio, no solo como textos historiográficos, sino también hagiográficos, épicos o genealógicos y, por supuesto, documentales. Estas obras, producidas en el seno de una comunidad y con su aprobación, sirven a sus intereses y a su particular visión de determinados acontecimientos. Muchas veces, estos textos surgían en circunstancias en las que era necesario demostrar la antigüedad $\mathrm{y}$, en consecuencia, la legitimidad de la institución o proporcionarle cohesión e identidad ${ }^{2}$. Este análisis se puede hacer extensivo a los cartularios: superada la visión de que se tratan de una simple colección de documentos ${ }^{3}$, hoy se consideran un instrumento de conservación y ejercicio de autoridad, un medio de legitimación de las aspiraciones (dinásticas, territoriales, legales) de una comunidad o institución ${ }^{4}$.

Así pues, dentro de la redacción de textos históricos con finalidad legitimadora, P. Geary sitúa los cartularios entre gestión y "gesta”, es decir, entre la gestión patrimonial y archivística y la narración histórica que ensalza a un personaje o grupo, además de ayudar a la memoria y la conmemoración de los benefactores de una institución ${ }^{6}$. Su utilidad práctica, aunque obvia, no puede ser el único motivo para su elaboración, ya que por lo general no se les otorgaba el mismo valor que a las piezas originales ${ }^{7}$. En muchos casos

\footnotetext{
${ }^{1}$ Abreviaturas utilizadas: Archivo Capitular de Toledo = ACT; Archivo Histórico Nacional = AHN; Cartulario Toledo, Biblioteca Capitular de Toledo 42-20 = BCT 42-20

${ }^{2}$ Paxton 2002, pp. 96-98.

${ }^{3}$ Esto es lo que Geary 1993, pp. 15-16, ha denominado la "invisibilidad del cartulario".

${ }^{4}$ Rodríguez Llopis 1988, pp. 10-14.

${ }_{6}^{5}$ Nos referimos a Geary 1993, pp. 13-26.

${ }^{6}$ Chastang 2011, pp. 7-13.

${ }^{7}$ Diferentes estudiosos hacen hincapié en el hecho de que los cartularios no tenían valor probatorio en un juicio, como Sáez Sánchez 2006, pp. 171-199; Bouchard 2002,p. 25; Chassel 1993, p. 159; Morelle 1993, pp.95-97. Sin embargo, parece que en épocas más tardías, a partir de finales del XI, cuando fue confeccionada la mayor parte de los cartularios de Toledo a los que
} 
tampoco preservaban una cantidad representativa de documentos, ni los más importantes. Partiendo de esta base, los cartularios sirven para proteger derechos basados en su importancia, antigüedad o excelencia ${ }^{8}$. Esta reafirmación se produce de manera especial, siguiendo la misma lógica que para los textos históricos, cuando la comunidad se ve amenazada. Por tanto, la redacción de cartularios está motivada en muchos casos por motivos externos al centro de producción, como cambios políticos o sociales que afectasen a la estabilidad o la integridad patrimonial de una institución, o por motivos internos que deban ser justificados para hacerse efectivos, como un giro determinado en su política, nuevas aspiraciones económicas o políticas o mutaciones más o menos profundas de su naturaleza y funciones ${ }^{9}$.

Con todo, es preciso tener en cuenta que los cartularios, como cualquier texto, no persiguen un único objetivo, ni se pueden analizar desde un único punto de vista; además de ser un género textual específico y responder a unas prácticas discursivas preestablecidas, están íntimamente ligados a la historia y la identidad de la institución que los produce y tienen, por tanto, características individuales que se han de tener en cuenta. Sin embargo, este análisis del cartulario como obra unitaria, que bebe de lo historiográfico y lo legal, ha arrojado interesantes resultados en la investigación histórica en ámbitos y épocas muy diferentes; nuestra intención es, pues, aplicar esta misma visión y metodología al estudio del cartulario más antiguo producido en la catedral de Toledo.

El BCT 42-20 no solo conserva y transmite documentación privada y real relativa a la sede toledana, sino que también ofrece una visión de su historia y de la historia del periodo. El objetivo de este trabajo es analizar 42-20 como un producto con varias finalidades que se solapan, que configuran sus particularidades y su papel privilegiado como testigo de la historia de Santa María de Toledo. En primer lugar, ofreceremos una descripción del contexto de producción del volumen y lo compararemos con los otros cartularios. En segundo lugar, analizaremos cómo cumple su función historiográfica y qué datos nos da sobre las intenciones que guiaron su redacción. Veremos, para

nos referiremos en este trabajo, se documenta que diversos cartularios fueron admitidos como pruebas en litigios, Mendo Carmona 2005, p. 128-129, en especial n. 21. Se aduce como explicación un cambio en el sistema de copia de estos volúmenes, puesto que a partir del XI-XII las copias suelen ser íntegras y de mayor exactitud, y además el propio archivo, donde se redacta el cartulario, confiere fe a los documentos que custodia y a las copias que emite.

${ }^{8}$ Mendo Carmona 2005, pp. 122-123.

${ }^{9}$ Esta idea está recogida en numerosos estudios, como Martin 2009, pp. 144-146; Peterson 2009, pp. 653-682; Sáez Sánchez 2005, pp. 12-21; 2006, pp. 184-186; Bouchard 2002, pp. 22-32; Deflou-Leca 1997, pp. 183-207; Flammarion 1982, pp. 272-273; Walker 1971, pp. 144-145; también se podrían mencionar los diferentes estudios de Geary 1993, 1996 o Chastang 2001, 2006, 2009. 
empezar, cuál es el papel y la posición del autor del cartulario. A continuación, examinaremos cómo convierte una serie de documentos aislados en una narración histórica y la función de la organización de las piezas en la interpretación del conjunto. Por último, se presentarán las conclusiones y la bibliografía utilizada.

\section{El CARTULARIO BCT 42-20 EN LA PRODUCCIÓN CATEDRALICIA}

El BCT 42-20 (medidas 292x190 mm) fue copiado en el año 1190, como reza el prólogo (in hodiernum diem qui est sub era millesima ducentesima uicesima octaua, f. 1r), en el scriptorium de la catedral toledana. Está escrito en minúscula caligráfica por una sola mano. Tanto su materia escriptoria como la copia (a línea tirada, excepto las suscripciones de testigos) son de excelente calidad. En sus setenta y ocho folios contiene sesenta y tres documentos: privilegios reales en la primera parte, privilegios arzobispales y documentos privados en la segunda, todos relacionados con los bienes de la catedral. Las piezas se ordenan cronológicamente dentro de las secciones. Además, las secciones están introducidas por noticias históricas o breves textos explicativos ${ }^{10}$. En su mayor parte, exceptuando algunos documentos privados o resúmenes de cartas, las cartas vuelven a recogerse en cartularios posteriores producidos también en el mismo contexto de la catedral, no así las noticias históricas, que constituyen una rareza dentro de los cartularios del archivo catedralicio toledano.

En su análisis de los cartularios toledanos, Francisco J. Hernández divide los diez volúmenes que han llegado hasta nosotros en dos grupos: los que copian registros y constituciones y los que contienen bulas sobre la primacía ${ }^{11}$. BCT 42-20 entraría dentro del primer grupo; sin embargo, presenta diferencias con el resto de cartularios tanto por su contexto histórico de redacción como por sus particularidades morfológicas.

Los cartularios Madrid, AHN, 996B (s. XIII) y Madrid, AHN, 987B (1257 p. q.) se titulan ambos Liber priuilegiorum Ecclesiae Toletanae ${ }^{12}$. El primero copia un gran número de documentos y algunas bulas, sin agrupar las piezas según un orden preciso. También el segundo responde a las necesidades del archivo y a cambios en su gestión, como testimonia su organización,

\footnotetext{
${ }^{10}$ Descripción codicológica completa en Gonzálvez 1996, pp. XVI-XVII.

${ }^{11}$ Hernández 1996, pp. XXIII-XXVI. Para la descripción completa de los cartularios que se mencionarán a continuación, Gonzálvez 1996.

${ }^{12}$ Sobre estas denominaciones y su relevancia para el estudio de los cartularios, Bertrand, Bourlet, Hélary 2006, pp. 14-15.
} 
mucho más cuidada ${ }^{13}$. Según Hernández, sirvieron a finalidades archivísticas; sin embargo, no parecen tener las mismas características que BCT 42-20. De los cartularios elaborados en la catedral toledana, BCT 42-20 es el más breve: como se ha dicho, contiene sólo sesenta y tres documentos, mientras que, por ejemplo, el más extenso, 996B, transmite más de doscientos, muchos de ellos fechados con anterioridad a la redacción de BCT 42-20 y no recogidos por este. La selección de documentos de BCT 42-20, bastante restringida, se limita a una serie de privilegios y propiedades de entre las muchas de las que disfrutaba la sede toledana. Además, nuestro cartulario presenta otras características peculiares, como la cuidada organización de los documentos y la inserción de textos históricos explicativos ${ }^{14}$. Por tanto, aunque la copia de los documentos tiene intención facsimilar y se reproducen, con bastante exactitud, los crismones y rotas de los originales ${ }^{15}$, no podemos suponer que sirviese a finalidades archivísticas, o no exclusivamente.

Siguiendo a Hernández, tampoco se puede relacionar a BCT 42-40 con los cartularios que copian bulas relacionadas con la Primacía de Toledo. Tras la reconquista de la ciudad de Toledo por Alfonso VI en 1085, comienza una serie de dotaciones y alianzas encaminadas a reafirmar el poder del monarca en la ciudad y a contrarrestar el poder de la jerarquía eclesiástica mozárabe $^{16}$, al tiempo que multiplicaba el patrimonio y las rentas del clero cristiano ${ }^{17}$. Paralelamente, Bernardo de Cluny ${ }^{18}$, el nuevo arzobispo, consigue de Urbano II la primera de una sucesión de bulas que se referían a los derechos de la antigua metrópolis, Cunctis Sanctorum, de 1088/1089, en la que se reconoce la Primacía de la sede toledana; sin embargo, continuaron los conflictos con otras diócesis, que remontaban a la época visigótica ${ }^{19}$. Varios de los cartularios que contienen documentación del archivo catedralicio fueron redactados específicamente para avalar la primacía de la Iglesia de Toledo sobre el resto de las sedes de Hispania y se sitúan en fechas próximas a la celebración del IV Concilio de Letrán (1215), en el que se debate este derecho. Estos volúmenes recogen principalmente bulas y documentación eclesiástica e indican

\footnotetext{
${ }^{13}$ Miguel Franco 2015, pp. 125-129.

${ }^{14}$ Como ya notó Hernández 1996, p. XXV.

${ }^{15}$ Sáez Sánchez 1999, pp. 899-916; Chassel 1993, pp. 153-169; Morelle 1993, pp, 80-104.

${ }^{16}$ Sobre los fueros concedidos a los mozárabes, González Palencia 1926, pp. 118-120. Se establece una interesante comparación con el caso portugués en Aillet 2010, pp. 301-308.

${ }^{17}$ Rivera Recio 1974, pp. 117-121.

${ }^{18}$ Sobre este personaje, Rivera Recio 1962.

${ }^{19}$ Sobre la historia de la reivindicación de esta primacía, Gonzálvez 2006, pp. 383-438; Henriet 2004, pp. 291-319; Beltrán Torreira 1991, pp. 497-510; Feige 1991, pp. 61-132. El reflejo de esta lucha en los cartularios ha sido analizado por Gonzálvez 1996, p. XV; Rucquoi 1992, pp. 67-70; Rivera Recio 1962, pp. 30-38.
} 
con más precisión el contenido de estos privilegios (e indirectamente, el motivo de su compilación): Toledo, Biblioteca Capitular de Toledo, 42-21: Liber priuilegiorum de primatu Toletanae Ecclesiae (s. XIII); Toledo, BCT, 42-22: Liber priuilegiorum super primatu Toletanae Ecclesiae; Madrid, Biblioteca Nacional de España, Vitr. 15-5: Notulae de primatu, nobilitate et dominio Ecclesiae Toletanae $^{20}$. Vemos así que estos cartularios responden a los motivos que se han propuesto como determinantes para la confección de este tipo de obras: una situación de conflicto en la que una institución tiene que reafirmar sus derechos o privilegios. En el contexto de las aspiraciones toledanas a sede primada, estos cartularios están concebidos como producto historiográfico y legal y no solo archivístico.

BCT 42-20, es el cartulario más antiguo de los producidos en esta institución: fue escrito en el año 1190, como explicita el prólogo ${ }^{21}$; por su fecha y por la total ausencia de bulas papales relacionadas con la cuestión de la primacía, podemos imaginar que nada tuvo que ver en su redacción la celebración del Concilio de Letrán. Por tanto, como ya propuso Hernández 1996, debemos separar BCT 42-20 del bloque de cartularios que se relacionan con la primacía de Toledo y descartar este conflicto como motor para su producción $^{22}$.

Sin embargo, sí podemos relacionar el cartulario con otros acontecimientos diferentes. En la historia de la catedral de Toledo, sobre todo si atendemos a lo relativo a su patrimonio y organización, se han distinguido tres etapas principales, que tienen paralelismos en toda Europa ${ }^{23}$. En primer lugar, desde el restablecimiento del arzobispado de Toledo en 1086, tras la conquista de la ciudad en 1085 por Alfonso VI, Bernardo de Cluny organizó el clero catedralicio siguiendo un modelo monástico, tanto en lo espiritual como en lo material. Este fue el modo en el que, en general, se estructuraron las catedrales a partir de la reforma gregoriana ${ }^{24}$. En segundo lugar, a raíz de la creciente secularización del clero catedralicio y de los conflictos que ello provocaba, aproximadamente en 1136, se produjo la división entre la mesa episcopal y la mesa capitular, con diversos reajustes hasta finales del XII. La

${ }^{20}$ Sobre los títulos de estas compilaciones, Feller 2015, p. 200.

${ }^{21}$ Hernández 1996, pp. XVI-XVII; XIV.

${ }^{22}$ Como ya propuso Hernández 1996.

${ }^{23}$ Nos basamos en las propuestas de Rivera Recio 1974 para el caso toledano. Esta misma evolución es la que experimentan diversas catedrales francesas, con diferencias cronológicas y estructurales, Becquet 1989; Millet 1995, pp. 123-133.

${ }^{24}$ Sobre la expansión de la regularización ver Avril 1989, pp. 43-52; Parisse 2009 (y, en especial en este volumen, Vones-Liebenstein 2009). Esta reforma dio lugar también a la producción de algunos cartularios en otros ámbitos, Zerner 2006, pp. 165-166; Chastang 2001, pp. 221-307. 
partición se refleja en la estructura patrimonial de Santa María de Toledo y en la documentación producida. Desde finales del XII y sobre todo a principios del siglo XIII, la catedral comienza a constituirse en señorío, adquiriendo no solo derecho de propiedad sobre un determinado territorio, sino la facultad de ejercer ciertos actos de potestad jurisdiccional sobre ese territorio y sus pobladores $^{25}$. Por tanto, el cartulario se sitúa en los años posteriores a la división de las mesas, cuando la reorganización patrimonial estaba consumada y se estaban produciendo diversos reajustes económicos y de personal. Este es uno de los puntos de partida del análisis del cartulario: se sitúa en un periodo de cambios y reestructuración interna de la institución que lo produce. A continuación, trataremos de ver cómo las particularidades de BCT 42-20 se relacionan con este contexto histórico.

\section{LA CONSTRUCCIÓN DEL CARTULARIO CRÓNICA}

El cartulario BCT 42-20 es, como hemos apuntado, una obra de naturaleza mixta, que sirve a la vez para la conservación documental y como documento historiográfico. Así pues, nos hallamos ante un ejemplo de cartulario-crónica, un género intermedio entre el texto legal y el histórico, que aprovecha la importancia de los eventos pasados para establecer precedentes legales y para cimentar determinadas decisiones o privilegios ${ }^{26}$. Ese vínculo entre pasado y presente se establece de manera textual; el cartulario en sí es un mecanismo que convierte en narración las piezas documentales independientes.

En los cartularios-crónica podríamos establecer un continuum que iría desde la colección de documentos con algunas anotaciones o comentarios históricos, como el Tumbo de San Pedro de Montes (1283 p. q.), que añade a la copia de los documentos una pequeña narración de la historia del monasterio, además de pequeños resúmenes en romance de las cartas latinas ${ }^{27}$, hasta la prosa histórica que incluye fragmentos o documentos enteros, como, por ejemplo, el Libellus de rebus gestis Glastoniensibus, de Adam of Domerham (1291 p.q.), que mezcla documentación, como cartas relativas a las propiedades del monasterio de Glastonbury o rescriptos papales, con narración histórica en un modo en el que las fronteras textuales son difíciles de establecer ${ }^{28}$. A pesar de las diferencias, en ambos casos el documento recibe algún tipo de

\footnotetext{
${ }^{25}$ Rivera Recio 1974, p. 54.

${ }^{26}$ Dunphy 2012.

${ }^{27}$ Quintana Prieto 1971, para un estudio y edición de los documentos latinos.

${ }^{28}$ Se estudian los significados y la construcción de este cartulario en Sutherland-Harris 2012, pp. 107-123.
} 
tratamiento textual que permite su inclusión en un hilo narrativo ${ }^{29}$. El cartulario BCT 42-20 está más cerca del primer extremo: la copia de piezas documentales predomina sobre el texto histórico.

Así pues, los cartularios-crónica no solo transmiten, sino que también interpretan los documentos en esta labor de reorganización del pasado. En el cartulario BCT 42-20 la finalidad histórica se aprecia en tres aspectos diferentes, que iremos analizando por separado: en primer lugar, el papel que desempeña el autor o compilador del volumen; segundo, el texto que enmarca las piezas copiadas ${ }^{30}$; por último, la organización del volumen (que, por supuesto, presupone una selección previa) ${ }^{31}$, y que nos da la clave de su naturaleza e intenciones.

\subsection{El autor del cartulario}

En una anotación marginal en el último folio leemos: Robertus me fecit, f. $78 \mathrm{v}^{32}$. Tenemos muy pocos datos sobre la identidad de este personaje; en este caso, el hecho de que todo el volumen haya sido copiado por una sola mano $^{33}$, combinado con las intenciones literarias del prólogo y los textos que encuadran la copia de los documentos, nos lleva a pensar que este Roberto pudo ser el responsable de la compilación y no un simple escriba ${ }^{34}$. "Autor", en el caso de los cartularios (pero no solo), es un concepto lábil que lleva a replantearse las nociones de autoridad y obra, ya que hay, por lo menos, tres niveles de análisis: quién escribió cada documento; quién seleccionó, organizó y copió el conjunto; qué personaje o institución dispuso que se organizase y copiase ${ }^{35}$. Lo que llama la atención en este caso es que Roberto aparece en una anotación marginal, en la actualidad casi ilegible, en un lugar muy poco visible del cartulario. En cualquier caso, en este trabajo, por motivos de comodidad y brevedad, utilizaremos el nombre de Roberto para referirnos al responsable de la confección del cartulario, aunque no exista completa seguridad en su identificación.

\footnotetext{
${ }^{29}$ Más ejemplos de estrategias de textualización de las cartas en Morelle 2001.

${ }^{30}$ Miguel Franco 2015, pp. 120-123.

${ }^{31}$ Paradójicamente, la selección de piezas, que en ocasiones se relaciona con la desaparición de originales, es una labor de creación, Geary 2005, pp. 106-113.

${ }^{32}$ Todas las citas de documentos presentes en este trabajo proceden del cartulario BCT 42-20, por lo que nos limitaremos a señalar el número de folio.

${ }^{33}$ Es común también en otros cartularios relacionados con capítulos catedralicios, lo que los diferencia de los cartularios monásticos, que normalmente no responden a un único momento de redacción Chastang 2001, p. 38; p. 227. Para las relaciones "autógrafo-auctoritas", Arnaldi 1966, pp. 294-295.

${ }^{34}$ Ibidem, pp. 296-297, sobre un caso semejante de distinción entre cronistas y escribanos.

${ }^{35}$ Geary 2001 plantea estas cuestiones, centrando su análisis en tres cartularios diferentes.
} 
Uno de los rasgos más sobresalientes de BCT 42-20 es que se trata del único caso en el que se copian las firmas árabes de los documentos, añadiendo además la notación vocálica ausente de los originales ${ }^{36}$. También se incluyen menciones a otras cartas en árabe conservadas en el archivo, que el autor del cartulario lee y resume:

Habemus aliam cartam arabice scriptam in qua continetur quod praedicta domus apud alium erat in pignore, (f. 74r).

Priuilegium (...) de furno quem ipse Petro abbati (...) dedit (...) cum duabus etiam cartis arabicis quarum una est de compara ipsius loci, altera uero de compara curralis qui est furno contiguus (f. 69r).

Vemos así que el compilador era una persona versada en la lengua árabe y cercana a la institución catedralicia, lo que quiere decir que pertenecía, con casi total seguridad, a la comunidad mozárabe que ocupó numerosos puestos en el cabildo ${ }^{37}$.

Además, por su particular tipología, estas firmas árabes funcionan, junto con otros elementos de validación recogidos en los cartularios, (crismones o rotas), para darle autoridad a la copia de los documentos. Visualmente, son indicativos de una materialidad que solo alguien en las especiales circunstancias de Roberto podía conocer y transmitir ${ }^{38}$.

En diversos puntos del cartulario se enfatiza que el compilador de la selección pertenece a la institución representada, ya que conoce no solo las cartas que copia, sino su contexto y otras piezas semejantes conservadas en el mismo archivo. Esto se hace explícito en los regestos de los documentos, donde se ofrece información adicional no recogida en el texto del original copiado, a la que solo pudo tener acceso una persona cercana a la catedral de Toledo.

Por ejemplo, en la copia de la carta de donación que el conde Nuño y su esposa Teresa hacen de la mitad de la aldea de Alcavón y otros bienes para la dotación del altar de Santo Tomás se especifica dónde estaba construido este altar:

Priuilegium comitis Nunonis et Taresiae comitissae, uxoris eius, de medietate illius aldeae quae dicitur Alcauon et de domibus quae sunt in Zocadoueb cum alcazar contiguis, quas dedit Deo

\footnotetext{
${ }^{36}$ Sobre el bilingüismo árabe-latín en medios mozárabes, Aillet 2010, pp. 139-152 (especialmente pp. 142-143).

${ }^{37}$ Olstein 2011, pp. 151-186; Sassenscheidt 2011, pp. 125-150.

${ }^{38}$ Maxwell 1999, pp. 579, 581-582, 586. Sobre la utilización del árabe en los documentos toledanos, una aproximación reciente en Beale-Rivaya 2012.
} 
et ecclesiae Beatae Mariae de Toleto ad seruitium altaris Beati Thome martiris et episcopi Cantuariensis quod ipse in praedicta ecclesia uersus occidentalem partem aedificauit (f. 48r-v).

En el cuerpo del documento solo se dice:

altari sancti martiris Thome quod ex permisione domini Cenebruni (...) construi fecimus in ipsa ecclesia Toletana (ACT, A.2.G.1.1a, doc. $\left.180,1177^{39}\right)$.

Esto es, en el cartulario se añaden datos sobre la ubicación del altar dentro de la catedral y se precisa la identificación de este santo Tomás, obispo de Canterbury ${ }^{40}$, información que podría tener solo una persona que conociese personalmente la catedral de Toledo.

Otro ejemplo más del conocimiento de determinados detalles de la vida y economía capitular:

Carta de quarta parte uineae Alami, quae est in la Parada de Celencas; quam quartam partem canonici de redditibus anniuersariorum comparauerunt (f. 76r).

En la carta (doc. 142, 1164) se indica solamente que Martín Malo y sus hijos Salvador, Domingo y Doña venden dicha viña omnibus senioribus Sanctae Mariae Toletanae sedis y, como es habitual, los términos de la propiedad y su precio. Una vez más, la información del regesto no se encuentra en ningún otro punto del cartulario, ni procede de los documentos del archivo. Pero estas líneas también son importantes para la historia de la división de las mesas capitulares, en la que este cartulario ocupa un papel destacado. Según la constitución del arzobispo Juan de 1159, se otorgan en exclusiva a la mesa capitular las dotaciones de los aniversarios. Si las rentas de los bienes dotales fuesen superiores a los gastos de celebración, estas deberán invertirse en otros usos útiles o necesarios a la corporación ${ }^{41}$; en varias ocasiones, el sobrante de estos gastos se invirtió en comprar bienes inmuebles ${ }^{42}$. Solo una persona perteneciente a la mesa capitular podía saber que, en este caso, el importe pagado por la viña procedía del remanente de los bienes dotales.

${ }^{39}$ Se indica, la signatura del original de cada documento del Archivo Capitular de Toledo (abreviado como ACT), el número que recibe en el catálogo de Hernández 1996, a donde remitimos para más información, y el año. Si no se conserva el original, se da el número del catálogo y el año (por ejemplo, doc. 142, 1777).

${ }^{40}$ Cavero Domínguez 2012, pp. 281-302.

${ }^{41}$ Rivera Recio 1974, pp. 150-161.

${ }^{42}$ Ibidem, p. 168. 
Retomando lo expuesto más arriba, Roberto produjo este cartulario en 1190, cuando se había consumado la separación de las mesas capitular y episcopal. Como concluye P. Chastang, los canónigos son hombres sin pasa$d o$. Su identidad y sus derechos patrimoniales no pueden apoyarse, como en el caso de las instituciones monásticas, en la santidad de su fundador o en la posesión de reliquias. Son numerosos los conflictos con el poder episcopal o con monasterios que fueron con toda seguridad desencadenantes de la producción de cartularios en medios catedralicios ${ }^{43}$. Roberto reafirma su pertenencia a un grupo, esto es, al cabildo de Toledo, mediante el conocimiento de su funcionamiento interno, a la vez que construye su identidad colectiva y cimienta sus derechos mediante mecanismos textuales que pasan por la relectura del pasado común recogido en la documentación.

De los ejemplos presentados, que constituyen solo una pequeña muestra de los que se podrían extraer del cartulario, se obtienen dos conclusiones. En primer lugar, los regestos e introducciones a los documentos fueron redactados por una persona que conocía no solo estos pergaminos, sino también su contexto: los bienes que nombraban, su situación y su historia. Roberto se sitúa dentro de la institución a la que pertenece el cartulario y, muy importante desde el punto de vista historiográfico, es testigo ocular de los acontecimientos que narra y demuestra conocer bien los originales copiados, lo que proporciona legitimidad y autoridad al volumen ${ }^{44}$. Roberto es autor personal de los regestos y de la redacción de las indicaciones históricas, además del prólogo; es el que organiza los documentos y los resume. En el prólogo, que se analizará a continuación, se indica que la intención del conjunto es demostrar la magnificencia de las donaciones que se efectuaron a la catedral toledana a partir de la reconquista de la ciudad; por tanto, la autoridad detrás de la autoría de Roberto es la catedral en sí, aunque no se afirme explícitamente ${ }^{45}$. Por otra parte, este tipo de indicaciones refuerza la utilidad del cartulario en la gestión de los bienes de la catedral, ya que relaciona unas piezas con otras mediante enlaces intratextuales, pero también con el mundo exterior, no solo con sus coordenadas concretas de producción, sino con todo el patrimonio y la gestión de la sede de Toledo ${ }^{46}$.

${ }^{43}$ Chastang 2001, pp. 225-241.

${ }^{44}$ Chastang 2009, pp. 118-119; Genet 1977, pp. 95-96, 104-105.

${ }^{45}$ A diferencia de otros cartularios redactados por indicación de un obispo, Geary 2001, pp. 67-70. Quizá al actuar en nombre de una colectividad (la mesa capitular), Roberto se refiere simplemente a "la catedral", sin mencionar ningún nombre en concreto y casi ocultando el suyo.

${ }^{46}$ Sutherland-Harris 2012, p. 108. 


\subsection{Del documento al cartulario}

Como se ha repetido en varias ocasiones, la labor del compilador en este cartulario trasciende ampliamente la simple selección y copia de una serie de piezas ${ }^{47}$. La integración de una pieza documental en un cartulario, becerro o tumbo, transforma su naturaleza textual, ya que el cambio de soporte del documento modifica la relación que se establece entre el texto y su lector ${ }^{48}$.

En diversos estudios sobre cartularios se ha hablado de un proceso de "textualización" o "narrativización" de los documentos ${ }^{49}$. Este proceso se puede realizar de diferentes maneras y puede afectar más o menos al original ${ }^{50}$. En primer lugar, hay que atender a la inclusión todo lo que se denomina paratexto, como introducciones, prólogos o títulos, notas, que, además de proporcionar cohesión al conjunto, ofrecen al lector una guía de interpretación. En segundo lugar, la alteración o supresión de elementos del original durante el proceso de copia, que pueden llegar hasta la completa transformación, mediante paráfrasis o resumen, del texto original ${ }^{51}$. Finalmente, es crucial la selección y organización de las piezas, de la que nos ocuparemos en el siguiente apartado ${ }^{52}$.

Así pues, el texto no documental que encontramos en los cartularios (prólogos, títulos, regestos, indicaciones de cualquier tipo) es de la máxima importancia, ya es son el cartulario propiamente dicho y constituye la base del volumen ${ }^{53}$. Además, en el caso de BCT 42-20, los textos de unión son más abundantes y extensos que en los otros cartularios que hemos mencionado y es clara su intención de organizar las piezas en un todo. Nuestro cartulario empieza con un pequeño prólogo, con unas características peculiares. Los prólogos e introducciones de los cartularios han sido, dentro de los textos no diplomáticos que contienen, las piezas más estudiadas, aunque es común que las ediciones prescindan de ellos. Su importancia es crucial, ya que no solo proporcionan indicaciones históricas sobre el momento de redacción del cartulario, sobre los motivos de su compilación o cómo está construido y cómo manejarlo, sino que constituyen verdaderas declaraciones de intenciones del

\footnotetext{
${ }^{47}$ Chastang 2009, pp. 119-120.

${ }^{48}$ Chastang 2001, pp. 17-18.

${ }^{49}$ Tomamos esta terminología y su significado aplicado a los cartularios de estudios como Bedos-Rezak 2010, pp. 43-60.

${ }^{50}$ Se podría comparar con lo estudiado por Morelle 2001, pp. 91-93.

${ }^{51}$ No nos referimos con ello a la inclusión de documentos falsos, frecuente en otros cartularios. Un primer cotejo de BCT 42-20 con los originales que transmite revela que copia es de gran exactitud, Miguel Franco 2013, pp. 189-192.

${ }^{52}$ Véase 3.3. La organización de los materiales.

${ }^{53}$ Miguel Franco 2015, pp. 117-119.
} 
volumen ${ }^{54}$. En los prólogos de los cartularios se activan los tópicos retóricos de los textos prefatorios, comunes a todo tipo de obras literarias y repetidos desde la Antigüedad, lo que da fe, una vez más, de que la naturaleza del cartulario no es únicamente la de gestión archivística ${ }^{55}$. El prólogo de BCT 42-20 además de ayudar a la comprensión del volumen, es una muestra del método que seguirá Roberto en su composición:

In Dei nomine et eius gratia. Incipit liber priuilegiorum quae a tempore domni Aldefonsi, illustrissimi Ispaniarum regis, filii Fredenandi regis, Toletana ecclesia habuit, usque in hodiernum diem, qui est sub era millesima ducentesima uicesima octaua. Iste rex gloriosus, Aldefonsus praedictus, cum suis septem continuis annis contra paganos fortiter praeliando, Toletum urbem imperialem potentissime cepit, et eam Christianae fidei, Deo annuente, mirabiliter subiugauit sub era millesima centesima uicesima tercia. Is etiam ecclesiam Beatae Mariae de Toleto, quando consecrata fuit, multis et magnis muneribus decenter dotauit, quae subscripta priuilegia manifestissime declarabunt. Incipiunt priuilegia.

In primis, priuilegium de dote quam fecit uenerabilis rex Aldefonsus ecclesiae Beatae Mariae de Toleto in consecratione ipsius (f. 1r).

En realidad, en este prólogo se pueden distinguir varias partes. Uno, encontramos una introducción cronológica que informa de la intención de todo el volumen (incipit liber (...) sub era millesima ducentesima uicesima octaua). Dos, una breve narración histórica de cómo sucedió la reconquista de Toledo por Alfonso VI (Iste rex gloriosus (...) sub era millesima centesima uicesima tercia). Tres, noticias de qué donaciones realizó este rey a la catedral, que se probarán con los documentos incluidos, es decir, una justificación de cómo se realiza la imbricación entre texto histórico y documento (Is etiam ecclesiam (...) manifestissime declarabunt). Finalmente, encontramos en esta página otro incipit, esta vez de la serie de documentos (Incipiunt priuilegia) y el regesto del primer documento (In primis, priuilegium de dote), separado del prólogo por una línea en blanco, lo que indica que prefacio y regesto de los documentos pertenecen, en la mente del copista-autor, a dos tipologías textuales diferentes.

La segunda parte del prólogo hunde sus raíces en la carta que se incluye a continuación: ACT O.2.N.1.1, doc. 2, 1086, en la que Alfonso VI concede una serie de territorios y privilegios a la sede metropolitana de Santa

${ }^{54}$ Bourgain, Hubert 1993, pp. 115-137.

${ }^{55}$ Chastang 2006, pp. 108-109. 
María de Toledo, recientemente reconquistada ${ }^{56}$. El documento comienza con una parte narrativa, bastante extensa, en la que se cuentan las etapas de la reconquista de la ciudad de Toledo y la intención que movió al monarca para tomarla:

Postquam parentum meorum, uidelicet patris mei regis Fredenandi et matris meae Sanciae reginae, Deus mirabili ordine mihi pactatum tradidit imperium, bellum contra barbaras gentes asumpsi. A quibus post multa praelia, et post innumeras hostium mortes, ciuitates populosas et castella fortissima, adiuuante Dei gratia, cepi. Sicque, inspirante Dei gratia, exercitum contra istam urbem moui (...) ego Adefonsus imperator, duce Christo, eiusdem fidei cultoribus reddere possem; quam ob rem, amore cristianae religionis, dubio me periculo submittens, nunc magnis et frequentibus praeliis, nunc ocultis insidiarum circumuenientibus, nunc uero apertis incursionum deuastationibus, septem annorum reuolutionem gladio et fame (...) abitatores afflixi, quippe ipsi indurati ad sui desiderii maliciam iram Domini super se publica infestatione prouocauerunt. Idcirco timor Domini et mentis inualitudo irruit super eos. Quibus rebus coacti, ipsimet ianuas urbis mihi patefecerunt, atque imperium, quod uictores prius inuaserunt, uicti perdiderunt (ACT, O.2.N.1.1, doc. 2, 1086).

Como se puede apreciar, este documento podría realizar por sí mismo las funciones de prólogo a todo el conjunto de cartas posteriores. No es baladí el hecho de que esta carta se incluya en primer lugar, ya que no solo es la primera cronológicamente, sino que se trata de un documento crucial para la dignidad de la sede: la parte inicial, lugar tradicionalmente marcado dentro de una obra, se reserva para las piezas de mayor importancia ${ }^{57}$. Se trata además de un interesante caso de reutilización de un texto documental, es decir, de reciclaje de un documento como base para un prólogo, con la particularidad de que material fuente y reelaboración narrativa se hallan casi en los mismos folios del mismo cartulario ${ }^{58}$. Es decir, el prólogo dirige directamente al documento que se transcribe a continuación y forma con él una unidad; en conjunto, son leídos como prosa histórica. Además, vincula conceptualmente este documento fundacional con el resto de cartas que lo siguen, al presentarlos como una sucesión ininterrumpida que arranca de esa primera dotación y llega hasta el momento de redacción del cartulario.

La primera sección, dedicada a la documentación real, se divide a su vez en apartados que incluyen un número variable de cartas, organizadas

\footnotetext{
${ }^{56}$ Este documento está editado en Rivera 1963, doc. 1; García Luján 1982, doc. 1.

${ }^{57}$ Chastang 2001, p. 65; Zerner 2006, p. 201.

${ }^{58}$ Diferentes ejemplos en Chastang 2009, pp. 136-140.
} 
por reinados. Cada uno de estos bloques está precedido por breve prólogo que nos ofrece algunos datos sobre el monarca cuyos privilegios se introducen. Es interesante comprobar que existe una neta distinción entre los párrafos redactados por el autor-compilador y los documentos copiados, realizada con mecanismos visuales: el primero se subraya en rojo, de modo que se puede distinguir a simple vista la introducción y el texto del documento, y los regestos que, como es habitual, se rubrican en la misma tinta:

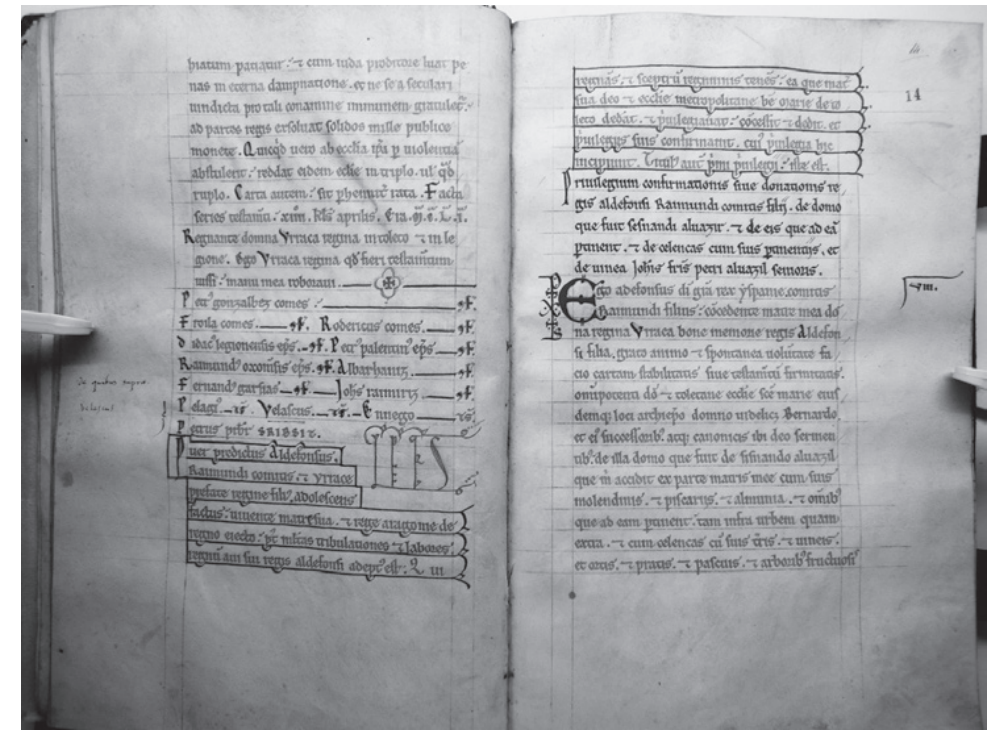

Fig. 1. BCT 42-20, ff. 13v-14r.

La parte enmarcada con líneas (en tinta roja en el manuscrito) constituye un prólogo al reinado de Alfonso VII:

Puer praedictus Aldefonsus, Raimundus comitis et Urracae praefatae reginae filius, adolescens factus, uiuente matre sua et rege Aragoniae, de regno eiecto, post multas tribulationes et labores regnum aui sui, regis Aldefonsi, adeptus est. Qui regnans et sceptrum regiminis tenens, ea quae mater sua Deo et ecclesiae metropolitanae Beatae Mariae de Toleto dederat et priuilegiauerat, concessit et dedit, et priuilegiis suis confirmauit.

Vemos la presentación de la serie documental completa (cuius priuilegia hic incipiunt) y la introducción al primer documento (titulus autem primi priuilegii iste est). En cambio, el regesto del documento que se copia a continuación: 
Priuilegium confirmationis siue donationis regis Aldefonsi, Raimundi comitis filii, de domo que fuit Sesnandi Aluazir et de eis quae ad eam pertinent, et de Celencas cum suis pertinentiis, et de uinea Iohannis, fratris Petri Aluazil senioris (doc. 2059, 1118)

igual que todo el resto de introducciones a las piezas, no se enfatiza de este modo ${ }^{60}$, sino que se rubrica, de modo que se marca la separación visual entre las piezas, al igual que en muchos otros cartularios de épocas y procedencias diversas ${ }^{61}$. Así pues, el cambio de color de la tinta, o diferentes marcas visuales, como el subrayado en rojo, sirven para dividir las diferentes secciones y guiar al lector.

Esta nota histórica es de gran importancia: refleja los intereses historiográficos del compilador, ya que Alfonso no reinaba en esa época ${ }^{62}$. Sin embargo, este comentario sirve para exaltar la figura de su nieto Alfonso VIII, durante cuyo reinado se redacta el cartulario. La intención de Roberto no es solo situar cada carta en su momento histórico, sino vincular la sede de Toledo con la historia de la Hispania del momento y sus reyes, con el fin de presentar los privilegios como un acontecimiento relevante en los reinados y subrayar su importancia ${ }^{63}$.

Si pasamos ahora a las introducciones de los documentos, observamos que reciben mucha atención, son extensas y están muy cuidadas; son verdaderos regestos, a diferencia de otros cartularios producidos en el $\mathrm{Ar}$ chivo Capitular de Toledo, como Madrid, Archivo Histórico Nacional, 996B (s. XII), que mayoritariamente incluye breves frases del tipo De Cidello aldea data populatoribus, f. 71v. Los títulos de los documentos son, quizá, uno de los elementos más interesantes de los cartularios, pero tradicionalmente han recibido muy poca atención por parte de los estudiosos, a diferencia de lo que ocurre con los títulos y epígrafes de las obras literarias, cuya importancia para su estudio y el de su tradición ha sido puesta de manifiesto en numerosas ocasiones $^{64}$. Es digno de destacar, por ejemplo, el esfuerzo por integrar la información proporcionada en la narración (sea en la narración histórica, sea en los regestos), mediante la utilización de demostrativos o los participios prae-

\footnotetext{
${ }^{59}$ No se conserva el original, sino una copia imitativa del XII-XIII, ACT Z.12.A.1.2.

${ }^{60}$ Este no es el único caso de texto subrayado con estos fines, ya que los documentos narrativizados que comentábamos en el apartado anterior también lo presentan en ocasiones, como en el f. 74r (véase 3.2. Del documento al cartulario).

${ }^{61}$ Rodríguez Díaz 2011, p. 23.

${ }^{62}$ Hernández 1996, p. XX.

${ }^{63}$ También en las obras históricas que incluyen documentos copiados de forma literal se cuidan especialmente estas introducciones, que parafrasean las cartas, Morelle 2001, p. 92.

${ }^{64}$ Bádenas Población 2011,pp. 335-358.
} 
dictus/praefatus, sea referidos a las personas que son a la vez protagonistas de la crónica histórica y del acto documentado o a los bienes que pasan a manos de Santa María de Toledo:

Priuilegium praedicti regis Aldefonsi de ecclesiis maioribus in singulis ciuitatibus et castris et uillis citra serram, quas mauri maiores mesquitas appellauerunt, cum omnibus pertinentiis suis (f. $4 \mathrm{v}$, doc. 6,1089 ).

Priuilegium praefati regis Aldefonsi ut palatia Toletani archiepiscopi ita sint honorata (f. 6v, ACT, A.6. B.2.3, doc. 12, 1103).

Por lo que respecta a la identificación de los monarcas (encontramos a Alfonso VI, Urraca, Alfonso VII y Alfonso VIII), reciben, en la gran mayoría de los regestos introductorios de los documentos, un mismo título o frase identificativa, extraído por lo general del texto de las cartas y relativo a la genealogía de la casa real. Alfonso VI es denominado filius Fredenandi regis; Urraca, es Urraca regina, filia Aldefonsi regis; Alfonso VII es Raimundi comitis filius en algunas cartas; en la mayor parte, se le denomina Aldefonsus rex. Por su parte, Alfonso VIII es imperator Aldefonsus. Tanto los demostrativos como la sinonimia son elementos de cohesión lingüística que sirven, en este caso, para construir la continuidad histórica de los documentos como etapas de un solo hilo argumental

Lo mismo se aprecia en los documentos privados. Cuando una propiedad pasa por varias manos antes de ser donada a la catedral, por ejemplo, si se trata de una donación real a un particular que posteriormente deja en herencia al cabildo, es habitual que los cartularios señalen brevemente este hecho. Esto también sucede en los cartularios Madrid, AHN, 996B y Madrid, AHN, 987B, que, como dijimos más arriba, también copian documentación privada. En el caso de BCT 42-20, podemos señalar, entre otros muchos, el siguiente ejemplo:

Priuilegium quod fecit domnus Aldefonsus, Ispaniarum imperator, Petro Sancti Pauli, corrigiario, de quadam tenda que est in ipsis corrigiariis, quam ipse Petrus postea uendidit Petro Moredae, qui eam ecclesiae Sanctae Mariae pro anniuersario suo dedit (f. 71r).

Carta de uenditione praefatae domus praedicti Petri Sancti Pauli, quam ipse Petro Moredae uendidit, qui eam in pignore diu tenuerat (f. 72r).

Testamentum Petri Moredae, in quo canonicis Santae Mariae praedictam domum pro anniuersario suo, sicut iam superius dictum est, dedit (f. 72r). 
Estos cuatro documentos que se refieren a una casa con su tienda que Alfonso VII donó a Pedro de San Pablo, quien la vendió a Pedro Moreda, que finalmente la donó a Santa María por su aniversario. Se aprecia, una vez más, el esfuerzo por integrar las tres piezas en una única historia; además de la introducción global en el primer documento, destaca la frase final sicut iam superius dictum est.

Finalmente, vemos en la parte correspondiente a las donaciones privadas un caso de conversión total, que transforma dos documentos en narración. En las crónicas, la autenticidad material del documento se separa de la autenticidad de los hechos narrados ${ }^{65}$; aquí vemos cómo la noticia de los hechos, convertida en narración, funciona como verdadera en un plano distinto de la carta original. Después de un documento en el que se describe cómo Arnaldo de Corbín, canónigo de Santa María, recibió una casa en prenda, se narra la historia del edificio, que fue puesto a la venta en almoneda al no satisfacer la deuda los dueños. No se copian los documentos, sino que se va contando cómo pasó esta casa a poder de Arnaldo de Corbín, en qué circunstancias y cómo la donó posteriormente a la catedral, resumiendo una carta en árabe y otra en latín ${ }^{66}$ :

Habemus aliam cartam arabice scriptam in qua continetur quod praedicta domus apud alium erat in pignore pro XIIII morabetinos minus quarta. Et etiam praedicta domus pro supranominatis debitis fuit posita in almuneda, et suo tenore uendita, mandato domini Iuliani Iben Bazo, tunc temporis alcalde, pro XXV morabetinos. De quibus redditis, XIIII morabetinos ab emptore, illi qui eam habebat in pignore; residuum Arnaldus de Corbin accepit, et integrauit se de illo auro, de IIII kafizes tritici et III kafizes ordei. Et recepit Arnaldus de Corbin praefatam domum ab emptore pro supranominato pretio et pro residuo tritici, quod supra ipsam domum habebat. Iterum habemus testamentum eiusdem Arnardi de Corbin, in quo Deo et ecclesiae Beatae Mariae pro anniuersario suo praedictam domum dedit, uel illud quod super illam habebat (ff. 74r-v).

Así pues, la intervención sobre los documentos copiados, ya sea mediante su inserción en un marco textual creado ad hoc, ya sea mediante su transformación en narración, los convierte en un todo homogéneo, que ilustra un aspecto concreto de la historia de la catedral de Toledo.

\footnotetext{
${ }^{65}$ Arnaldi 1976, p. 8.

${ }^{66}$ Copia coetánea del testamento de Arnaldo de Corbin, ACT I.4.A.1.27, doc. 157, 1170.
} 


\subsection{La organización de los materiales}

En las obras compuestas de elementos individuales, la selección de los materiales (especialmente relevante en el caso de fondos archivísticos) y su organización son los mecanismos principales para su creación y los factores que más información aportan a la hora de analizarla. La organización funciona conjuntamente con la inserción de paratexto entre las piezas, comentada en el apartado anterior, ya que son los títulos de las secciones, las llamadas, los índices, los que dan fe de esta disposición y de las intenciones tras ella ${ }^{67}$.

La estructura de BCT 42-20 es fruto de una cuidadosa labor de organización ${ }^{68}$. En primer lugar, hay una distinción primaria según el tipo de emisor del documento entre monarcas, por un lado, y obispos y laicos, por otro. Sin embargo, como es corriente, esta división bipartita general no se respeta escrupulosamente, ya que se agrupan las piezas sobre un mismo tema o una misma propiedad ${ }^{69}$. Así pues, la primera parte (ff. 1r-56v) está integrada por privilegios reales, según anuncia el prólogo que se ha analizado:

Incipit liber priuilegiorum quae a tempore domni Aldefonsi illustrissimi Ispaniarum regis, filii Fredenandi regis, Toletana ecclesia habuit usque in hodiernum diem (f. 1r).

Los documentos están agrupados en reinados, introducidos por textos más o menos extensos que describen sus principales características o acontecimientos. Es decir, dentro de una primera división por emisor encontramos una segunda división cronológica. La sucesión de reyes en el trono crea un contexto histórico para los documentos; a la vez, es cada uno de estos conjuntos de documentos los que narran el reinado de cada monarca. A pesar de que las piezas estén perfectamente datadas, para que constituyan una historia es necesario proporcionarles un marco cronológico que expanda su validez más allá de su uso legal ${ }^{70}$. La historia se crea mediante la cuidadosa disposición de una serie de piezas, que se convierten en crónica de las relaciones de cada

\footnotetext{
${ }^{67}$ Chastang 2011, pp. 16-20.

${ }^{68}$ Miguel Franco 2012 para un estudio de la organización y la copia en los diferentes cartularios de Toledo.

${ }^{69}$ Por ejemplo, en los ff. 48r-49v, en la parte dedicada a los privilegios reales, se incluye el documento 180,1177, en el que el conde Nuño y su mujer Teresa donan la aldea de Alcavón a Santa María. El motivo de que este documento privado se encuentre entre los reales es claro: en los folios siguientes, ff. 49v-50v, encontramos el documento 184, de 1178, en el que Alfonso VIII confirma esta donación. Este tipo de agrupaciones geográficas son muy frecuentes, Chastang 2011, p. 13; Bouchard 2002, p. 28; Genet 1977, pp. 104-105; Walker 1971, pp. 134-135 también en combinación con el orden cronológico, Feller 2015, pp. 200-204.

${ }^{70}$ Arnaldi 1976, pp. 10-12.
} 
monarca con la sede toledana; además, la memoria de la institución está indisolublemente ligada a la memoria de sus propiedades ${ }^{71}$.

A continuación encontramos otra sección compuesta por privilegios arzobispales y documentos privados, que lleva su propio prólogo ${ }^{72}$ :

Incipiunt priuilegia archiepiscoporum et aliorum Dei fidelium qui hereditates uel alia aliqua bona pro remedio animarum suarum, siue etiam pro anniuersariis suis a Dei ministris annuatim celebrandis, Deo et ecclesiae Beatae Mariae de Toleto pie et misericorditer contulerunt (f. 57r).

Lo principal es que el cartulario, en su disposición bipartita de las piezas, está asociando a obispos y a laicos, lo que reviste gran importancia en la comprensión de la estructura conceptual del volumen. Para empezar, los arzobispos y los demás fieles (archiepiscoporum et aliorum Dei fidelium) conceden bienes (hereditates uel alia aliqua bona) a la iglesia catedral de Toledo (Deo et ecclesiae Beatae Mariae de Toleto), por la salvación de su alma y la institución de aniversarios (pro remedio animarum suarum, siue etiam pro anniuersariis suis a Dei ministris annuatim celebrandis). Se aprecia así que el cartulario sirve a la conmemoración de los benefactores de la institución. uno de los objetivos que se han propuesto para este tipo de textos ${ }^{73}$, ya que la celebración de los aniversarios era una de las principales atribuciones del cabildo catedralicio ${ }^{74}$, aspecto en el que eran en cierto modo independientes del obispo.

Sin embargo, en los documentos que se inscriben en la segunda parte del cartulario BCT 42-20 se pueden encontrar dos bloques muy diferentes entre sí. Justo después de la introducción encontramos los siguientes documentos:

f. 57r: Priuilegium domni Raimundi Toletanae sedis archiepiscopi quod ipse eiusdem ecclesiae canonicis fecit de diuisione reddituum archiepiscopalium ad inuicem facta (ACT, Z.1G.1.1, doc. $39,1138)$.

f. 59r: Priuilegium domni Iohannis bonae memoriae Toletani archiepiscopi et Hispaniarum primatis quod ipse canonicis fecit de

${ }^{71}$ Feller 2015, p. 198.

${ }^{72}$ Esta misma separación de documentos según su emisor se aprecia en otros cartularios, Flammarion 1982, pp. 297-298. También es frecuente que se agrupen por abades u obispos, Bouchard 2004, p. 9 o incluso por tipo de documento, Martin 2009, pp. 148-153.

${ }^{73}$ Geary 1993, pp. 17-18; 1996, pp. 84-87.

${ }^{74}$ Esta conmemoración de los muertos en las catedrales tenía diferentes aspectos y destinatarios, Fournié 1995, p. 273. 
donatione de Ilesques et de Fazania (ACT, O.7.A.1.4, doc. 127, 1159).

f. 60r: Priuilegium domni Iohannis piae recordationis Toletanae sedis archiepiscopi et Hispaniarum primatis quod ipse canonicis iusdem sedis fecit de donatione hereditatum et aliorum donorum quae a Deo deuotis et bonis uiris pro anniuersariis suis annuatim faciendis Deo et Beatae Mariae de Toleto nuncusque relicta sunt et ammodo relinquentur (ACT, A.5.A.1.14, doc. 126, 1159).

f. 61r: Priuilegium domni Celebruni Toletanae sedis archiepiscopi et Hispaniarum primatis de numero canonicorum (ACT Z.1.G.1.3, doc. 165,1174$)$.

Se trata de los cuatro documentos principales que marcaron la separación entre la mesa episcopal y la mesa capitular ${ }^{75}$ : la primera constitución de Cerebruno, la donación del arzobispo Juan de Illescas y Azaña al cabildo, la concesión de Juan de los bienes dotales de los aniversarios al cabildo y la constitución de Cerebruno, que establece el número máximo de canónigos de la mesa capitular. El documento referente a las villas de Illescas y Azaña no era una donación en sí, sino la aplicación práctica del documento 159 a los bienes dotales de Sancho III y su padre Alfonso VII. Si consideramos el bloque de regulaciones dentro del conjunto del cartulario, vemos que es, en cierto modo, ajeno al resto de la documentación. Tanto los monarcas, en la primera parte del cartulario, como los "fieles de Dios" de la segunda parte, legan sus propios bienes para la celebración de los aniversarios. Pero en el caso de los documentos contenidos entre los folios 57r-60r, los arzobispos no añaden nada al patrimonio catedralicio, sino que se segrega la administración de una parte preexistente para atender a las necesidades de esta mesa capitular compuesta por clero secular, que ya no participaba de una vida en común de corte monástico ${ }^{76}$. Es más, la única carta arzobispal que realmente documenta una donación para un aniversario es el doc. 183, 1178, en el que Cerebruno concede la aldea de Cortes para la fundación de su aniversario. Este texto no está situado junto con el resto de privilegios de los prelados, sino que se inserta en el f.64r, entre documentos emitidos por laicos, de modo que se equipara a estos y se separa de las constituciones arzobispales.

Sin embargo, desde el punto de vista de la construcción del cartulario, el análisis de la organización y presentación de estos documentos, como práctica discursiva, debe separarse de su consideración desde el punto de vista

\footnotetext{
${ }^{75}$ Rivera Recio 1974, pp. 158-161.

${ }^{76}$ Venturini 2009 agrupa diferentes cartularios franceses según reflejen los intereses del clero regular (pp. 26-30) o secular (pp. 21-26).
} 
legal e histórico. En primer lugar, porque, sin serlo, las regulaciones de las mesas son insertadas dentro de una serie de donaciones con vistas a honrar la dignidad de la sede toledana y a conmemorar los aniversarios de determinados fieles. En segundo lugar, porque esta presentación condiciona su lectura y su interpretación: separa conceptualmente a los arzobispos de la catedral, colocándolos al mismo nivel que los donantes externos a la institución que otorgan beneficios a los canónigos. Las crónicas históricas son un instrumento para la validación (o invalidación) de documentos y privilegios ${ }^{77}$; así, la creación de este cartulario crónica recontextualiza los documentos arzobispales para delimitar su alcance.

Por tanto, aunque se presenten como pertenecientes a una misma serie de dotaciones para aniversarios, los primeros documentos, que fundan y regulan la mesa capitular, no están al mismo nivel que el resto del bloque ni pueden encuadrarse bajo el mismo título. Roberto parecía ser consciente de ello al agrupar la regulación de las mesas por un lado y las donaciones por otro. Pero, al asociar a los arzobispos con los demás fieles, se acrecienta también su separación del capítulo. A este respecto, el obispo se presenta como "externo" a la catedral, que se identifica exclusivamente con el cabildo, y se sitúa más bien entre los monarcas y los habitantes de Toledo que legaron sus bienes a Santa María. La selección y disposición de los documentos de esta segunda parte confirma la idea apuntada en la introducción: el cartulario sirve para la creación de la identidad del cabildo catedralicio de Toledo y para la legitimación de sus prebendas durante el proceso de separación de las mesas capitular y arzobispal.

Finalmente, al presentar todos los documentos como una serie ininterrumpida, ordenada a lo largo de un eje cronológico, que arranca con la dotación fundacional en 1086, y otro eje jerárquico, que empieza por los monarcas, sigue por los arzobispos y termina con laicos, todas las donaciones parecen ser equivalentes e ir a parar a las mismas manos. Sin embargo, hay que distinguir varias épocas en la constitución del patrimonio de la mesa capitular. En fecha aproximada de 1136, el arzobispo Raimundo concede al cabildo, entre otras cosas, la tercera parte de todas las rentas presentes y futuras de Santa María de Toledo. Por tanto, esta medida se aplicaba a todos los bienes mencionados en la documentación contenida en el cartulario anterior a esa fecha: aunque se mencionase al arzobispo, los canónigos y Santa María, la administración estaba dividida ${ }^{78}$. En segundo lugar, a partir de la reordenación de 1159, el obispo Juan prescribe que los bienes dotales de aniversarios pasasen íntegramente a

${ }^{77}$ Arnaldi 1976, pp. 6-7.

${ }^{78}$ Rivera Recio 1974, pp. 135-139; 158-159. 
la mesa capitular ${ }^{79}$, en consonancia con el surgimiento de nuevas formas de culto y conmemoración de los difuntos en las que el cabildo tenía gran reponsabilidad $^{80}$. Así pues, las donaciones a tal efecto documentadas en el cartulario eran propiedad exclusiva de los canónigos. En BCT 42-20 se asocian ambos tipos de propiedad y se presentan todos los documentos como equivalentes; la bisagra entre una y otra, representada por las fundaciones de la mesa capitular que inauguran la segunda parte del volumen, se añade también al conjunto heterogéneo de donaciones.

En resumen, gracias a la organización de los documentos y a su presentación en bloques, las donaciones a la Catedral desde la reconquista de Toledo y la separación de las mesas episcopal y capitular se unifican a nivel textual como etapas de un mismo proceso histórico.

\section{CONCLUSIONES}

Para finalizar este trabajo, podríamos recoger la afirmación de Bedos-Rezak, que sugiere que los copistas medievales de cartularios, especialmente en casos como el de nuestro Roberto, demostraban que su objetivo era menos la reproducción de las pruebas de los actos o hechos documentados que la canonización de estos hechos como prácticas discursivas ${ }^{81}$. Este proceso discursivo se inserta en la construcción de la conmemoración y la historia, junto con la gestión de los instrumentos que legitimaban y cimentaban la identidad y el poder de la institución ${ }^{82}$. El cartulario BCT 42-20, es, por tanto, una buen ejemplo de estas obras que trascienden la colección documental. Los documentos son las piezas de una construcción textual de carácter histórico y que, como casi toda la historia, tiene como finalidad la exaltación de la entidad que la produce.

En este caso, un miembro del cabildo propone una relectura de su historia a través de una serie de documentos cuidadosamente seleccionados y organizados, presentados por un marco textual que dirige la atención y la interpretación hacia unos objetivos concretos. Roberto se muestra como representante de una institución de creación reciente como es la mesa capitular y, por tanto, debe legitimar su pasado y cohesionar su identidad. Son dos los modos en los que esto se lleva a cabo: uno, mediante la demostración de la

\footnotetext{
${ }^{79}$ Ibidem, p. 160.

${ }^{80}$ Asociado probablemente al especial estatus de iglesia parroquial de las catedrales, Fournié 1995, pp. 288-290.

${ }^{81}$ Bedos-Rezak 2002, p. 54.

${ }^{82}$ Rodríguez Díaz 2011, pp. 32-33.
} 
antigüedad y la dignidad de la institución; dos, mediante la definición de los límites de la pertenencia al grupo. El cartulario BCT 42-20 consigue, a través de mecanismos textuales, unificar la historia de la sede de Santa María de Toledo desde su dotación fundacional en 1086 y la de la mesa capitular, presentándola como una única narración de acontecimientos semejantes. Del mismo modo, amalgama a reyes, arzobispos y particulares, marcando así las fronteras del cabildo: de un lado, los donantes; de otro, la catedral, identificada con la mesa capitular.

En conclusión, el análisis organizativo y narratológico del cartulario BCT 42-20 arroja datos sobre los motivos que movieron a su compilación. Este cartulario se sitúa en el proceso de partición de mesas capitular y episcopal y es a la vez instrumento y resultado de esta partición y este contexto de composición tiene su reflejo en las estrategias textuales elegidas. Una vez más, la creación de un cartulario surge en un momento de cambio en el que es necesario (re)construir el pasado y legitimar la identidad de la institución que lo produce.

\section{BIBLIOGRAFÍA}

Aillet, Cyrille (2010), Les mozarabes. Christianisme, islamisation et arabisation en Péninsule Ibérique (IX ${ }^{e}$-XII ${ }^{e}$ siècle), Madrid, Casa de Velázquez.

Arnarldi, Girolamo (1966), II notaio-cronista e le cronache cittadine in Italia, en La storia del diritto nel quadro delle scienze storiche. Atti del $1^{\circ}$ Congresso Internazionale della Società Italiana di Storia del Diritto, Florencia, L. S. Olschki, pp. 293-309.

Arnarldi, Girolamo (1976), Cronache con documenti, cronache "autentiche" e pubblica storiografia, "La Cultura. Rivista di Filosofia, Letteratura e Storia" 14, pp. 3-25.

Avril, Joseph (1989), La participation du chapitre cathédral au gouvernement du diocèse, "Cahiers de Fanjeaux" 24 (Le monde des chanoines. XI ${ }^{\mathrm{e}}$ XIVe siècles), pp. 43-63.

Bádenas Población, Ma José (2011), El índice del Libro Gótico de San Juan de la Peña. ¿Ordenar para administrar?, en Rodríguez Díaz, Elena E.; García Martínez, Antonio Claret (coords.), La escritura de la memoria: los cartularios, Huelva, Universidad de Huelva, pp. 335-358.

Beale-Rivaya, Yasmine (2012), The Written Record as Witness: Language Shift from Arabic to Romance in the Documents of the Mozarabs of Toledo in the $12^{\text {th }}$ and $13^{\text {th }}$ Centuries, "La Corónica" 40/2, pp. 27-50. Bedos-Rezak, Brigitte M. (2002), Towards an Archeology of the Medieval Charter: Textual Production and Reproduction in Northern French 
Chartriers, en Kosto, Adam J.; Winroth, Anders (eds.), Charters, Cartularies and Archives. The Preservation and Transmission of Documents in the Medieval West. Proceedings of a Colloquium of the Commission Internationale de Diplomatique (Princeton and New York, 16-18 September 1999), Toronto, Pontifical Institute of Mediaeval Studies, pp. 43-60.

Bedos-Rezak, Brigitte M. (2010), When Ego Was Imago: Signs of Identity in the Middle Ages, Leiden, Brill.

Beltrán Torreira, Federico M. (1991), El conflicto por la primacía eclesiástica de la cartaginense y el III Concilio de Toledo, en González Martín, Marcelo (ed.), Concilio III de Toledo: XIV Centenario: 589-1989, Toledo, Arzobispado de Toledo, pp. 497-510.

Becquet, Jean (1989), L'évolution des chapitres cathédraux: régularisations et sécularisations, "Cahiers de Fanjeaux" 24 (Le monde des chanoines. XI'-XIV siècles), pp. 19-39.

Bertrand, Paul; Bourlet, Caroline; Hélary, Xavier, Vers une typologie des cartulaires médiévaux, en Le Blévec, Daniel (ed.), Les cartulaires méridionaux. Actes du colloque organizé à Béziers, 20-21 septembre 2002, París, École National des Chartes, pp. 7-20.

Bourgain, Pascale; Hubert, Clotilde (1993), Latin et rhétorique dans les préfaces de cartulaires, en Guyotjeannin, Oliver; Parisse, Michel; Morelle, Laurent (eds.), Les cartulaires: Actes de la Table ronde organisée par l'École Nationale des Chartes et le GDR 121 du CNRS, Paris, 5-7 décembre 1991, París, École des Chartes, pp. 115-137.

Bouchard, Constance B. (2002), Monastic cartularies: Organizing Eternity, en Kosto, Adam J.; Winroth, Anders, Charters, Cartularies and Archives. The Preservation and Transmission of Documents in the Medieval West. Proceedings of a Colloquium of the Commission Internationale de Diplomatique (Princeton and New York, 16-18 September 1999), Toronto, Pontifical Institute of Mediaeval Studies, pp. 22-32.

Bouchard, Constance B. (2004), The Cartulary of Montier-en-Den, Toronto, University of Toronto Press.

Cavero Domínguez, Gregoria (2012), San Nicolás de Bari y Santo Tomás de Canterbury en la religiosidad del siglo XII, en Ruiz de la Peña Solar, Juan Ignacio; Sanz Fuentes, María Josefa; Calleja Puerta, Miguel (eds.), Los fueros de Avilés y su época, Oviedo, Real Instituto de Estudios Asturianos, pp. 281-302.

Chassel, Jean-Luc (1993), Dessins et mentions de sceaux dans les cartulaires médiévaux, en Guyotjeannin, Oliver; Parisse, Michel; Morelle, Laurent (eds.), Les cartulaires: Actes de la Table ronde organisée par 
l'École Nationale des Chartes et le GDR 121 du CNRS, Paris, 5-7 décembre 1991, París, École des Chartes, pp. 153-169.

Chastang, Pierre (2001), Lire, écrire, transcrire. Le travail des rédacteurs de cartulaires en Bas-Languedoc (XI ${ }^{e}-X I^{e}$ siècles), París, CTHS.

Chastang, Pierre (2006), La préface du Liber instrumentorum memorialis des Guilhem de Montpellier ou les enjeux de la rédaction d'un cartulaire laïque méridional, en Le Blévec, Daniel (ed.), Les cartulaires méridionaux. Actes du colloque organizé à Béziers, 20-21 septembre 2002, París, École National des Chartes, pp. 91-124.

Chastang, Pierre (2009), Transcription ou remploi? Composition et écriture des cartulaires en Bas-Languedoc (XII ${ }^{e}$ XIV siècle), en Toubert, Pierre; Moret, Pierre (eds.), Remploi, citation, plagiat. Conduites et pratiques médiévales ( $X^{e}-X I I^{e}$ siècle), Madrid, Casa de Velázquez, pp. 115-140.

Chastang, Pierre (2011), Des archives au codex: les enjeux de la rédaction des cartulaires $\left(X I^{e}-X I V^{e}\right.$ siècle) "Cahiers Électroniques d'Histoire Textuelle du LAMOP" 1 (Les regroupements textuels au Moyen Âge) [primera edición 2008], URL: http://lamop.univparis1.fr/IMG/pdf/ article_Pierre_Chastang--2.pdf [consulta: 9/06/2015].

Deflou- Leca, Noëlle (1997), L'élaboration d'un grand cartulaire au XIII ${ }^{e}$ siècle: le cas de Saint Germain d'Auxerre, "Revue Mabillon" 8/69, pp. 183-207.

Dunphy, Graeme (2012), Cartulary Chronicles and Legal Texts, en Encyclopedia of the Medieval Chronicle, URL: http://referenceworks.brillonline.com/entries/encyclopedia-of-the-medieval-chronicle/cartularychronicles-and-legal-texts-EMCSIM_01668 [consulta: 20/02/2015].

Feige, Peter (1991), La primacía de Toledo y la libertad de las demás metrópolis de España: el ejemplo de Braga, en La Introducción del Císter en España y Portugal, Burgos, La Olmeda, pp. 61-132.

Feller, Laurent (2015), Écrire l'histoire dans les monastères d'Italie centrale aux XI ${ }^{e}$ et XII ${ }^{e}$ siècles. Chroniques, cartulaires-chroniques et documents, en Anheim, Étienne; Chastang, Pierre; Mora-Lebrun, Francine; Rochebouet, Anne (dirs.), L'écriture de l'histoire au Moyen Âge. Contraintes historiques, contraintes documentaires, París, Garnier, pp. 59-73.

Flammarion, Hubert (1982), Une équipe de scribes au travail au XIII" siècle: le grand cartulaire du Chapitre Cathédral de Langres, "Archiv für Diplomatik" 28, pp. 271-305.

Fournié, Michelle (1995), Cathédrale et liturgie des défunts. Le cas de Lavaur et de Toulouse, "Cahiers de Fanjeux" 30 (La cathédrale, XII - XIV siècles), pp. 269-294. 
García Luján, José Antonio (1982), Privilegios reales de la catedral de Toledo (1086-1462), Toledo, Torres.

Geary, Patrick (1993), Entre gestion et Gesta: aux origines des cartulaires, en Guyotjeannin, Oliver; Parisse, Michel; Morelle, Laurent (eds.), Les cartulaires: Actes de la Table ronde organisée par l'École Nationale des Chartes et le GDR 121 du CNRS, Paris, 5-7 décembre 1991, París, École des Chartes, pp. 13-26.

Geary, Patrick (1996), Phantoms of Remembrance. Memory and Oblivion at the End of the First Millenium, Princeton, Princeton University Press.

Geary, Patrick (2001), Auctor et Auctoritas dans les cartulaires du haut Moyen Âge, en Zimmerman, Michel (ed.), Auctor et auctoritas: invention et conformisme dans l'écriture médiévale. Actes du colloque de Saint-Quentin-en-Yvelines, 14 juin 1999, París, École des Chartes, pp. 61-71.

Geary, Patrick (2005), Medieval Archivists as Authors: Social Memory and Archival Memory, en Blouin, Francis X.; Rosenberg, William G. (eds.), Archives, Documentation, and Institutions of Social Memory, Ann Arbor, University of Michigan Press, pp. 106-113.

Genet, Jean-Pierre (1977), Cartulaires, registres et histoire: l'exemple anglais, en Guenée, B., Le métier d'historien au Moyen Âge. Études sur l'historiographie médiévale, París, Publications de la Sorbonne, pp. 95-183.

González Palencia, Ángel (1926), Los mozárabes de Toledo, vol. 1, Madrid, Instituto Valencia de Don Juan.

Gonzálvez, Ramón (1996²), Prólogo, en Hernández, Francisco Javier, Los cartularios de Toledo, Madrid, Fundación Ramón Areces, pp. XIII-XXII.

Gonzálvez, Ramón (2006), La primacía de Toledo y su ámbito territorial, "Memoria Ecclesiae" 28/2 (Geografía eclesiástica hispana y archivos de la iglesia santoral hispano-mozárabe en las Diócesis de España. Actas del XIX Congreso de la Asociación, Santa Cruz de Tenerife-Las Palmas, 15- 20 de septiembre 2003), pp. 383-438.

Henriet, Patrick (2004), Political Struggle and the Legitimation of the Toledan Primacy: The Pars Lateranii Concilii, en Alfonso, Isabel; Kennedy, Hugh; Escalona, Julio (eds.), Building Legitimacy. Political Discourses and Forms of Legitimation in Medieval Societies, Leiden, Brill, pp. 291-319

Hernández, Francisco Javier $\left(1996^{2}\right)$, Introducción, en Hernández, Francisco Javier, Los cartularios de Toledo, Madrid, Fundación Ramón Areces, pp. XXIII-XXIX.

Martin, Jean-Marie (2009), Occasions et modalités du remploi dans les cartulaires-chroniques de l'Italie méridionale, en Toubert, Pierre; Moret, 
Pierre (eds.), Remploi, citation, plagiat. Conduites et pratiques médiévales ( $X^{e}-X I I^{e}$ siècle), Madrid, Casa de Velázquez, pp. 141-160.

Maxwell, Robert A. (1999), Sealing Signs and the Art of Transcribing in the Vierzon Cartulary, "The Art Bulletin" 81/4, pp. 576-597.

Mendo Carmona, Concepción (2005), El cartulario como instrumento archivístico, "Signo: revista de historia de la cultura escrita" 15, pp. 119-137.

Miguel Franco, Ruth (2012), Documentos originales y cartularios del Archivo de la catedral de Toledo: propuestas para un estudio comparativo, en Torrens Álvarez, M Jesuś; Sánchez-Prieto Borja, Pedro (coords.), Nuevas perspectivas para la edición y el estudio de documentos hispánicos antiguos, Berna, Peter Lang, pp. 197-218.

Miguel Franco, Ruth (2013), El cartulario Madrid, AHN, 996B del Archivo Capitular de Toledo. Aportaciones al estudio de la onomástica, en Casanova Herrero, Emili; Calvo Rigual, Cesáreo (eds.), Actas del XXVI Congreso Internacional de Lingüística y de Filología Románicas, Berlín - Boston, Walter de Gruyter, vol. 5, pp. 189-199.

Miguel Franco, Ruth (2015), Para una aproximación global al estudio de los cartularios toledanos: los textos no documentales, en Torre, Mariela de la; Sánchez, Juan Pedro (eds.), Problemas y métodos en la edición y el estudio de documentos hispánicos antiguos, Valencia, Tirant lo Blanch, pp. 117-133."

Millet, Hélène (1995), Les chanoines des cathédrales du Midi, "Cahiers de Fanjeux" 30 (La cathédrale, XII ${ }^{e}$-XIV" siècles), pp. 121-144.

Morelle, Laurent (1993), De l'original à la copie: remarque sur l'évaluation des transcriptions dans les cartulaires médiévaux, en Guyotjeannin, Oliver; Parisse, Michel; Morelle, Laurent (eds.), Les cartulaires: Actes de la Table ronde organisée par l'École Nationale des Chartes et le GDR 121 du CNRS, Paris, 5-7 décembre 1991, París, École des Chartes, pp. 91-104.

Morelle, Laurent (2001), La mise en oeuvre des actes diplomatiques: l'auctoritas des chartes chez quelques historiographes monastiques (IX ${ }^{e}-X I^{e}$ siècle), en Zimmermann, Michel (ed.), Auctor et auctoritas: invention et conformisme dans l'écriture médiévale. Actes du colloque de Saint-Quentin-en-Yvelines, 14 juin 1999, París, École National des Chartes, pp. 75-96.

Olstein, Diego (2011), The Mozarabs of Toledo (12 $2^{\text {th }}-13^{\text {th }}$ Centuries) in Historiography, Sources, and History, en Maser, Matthias; Herbers, Klaus (eds.), Die Mozaraber: Definitionen und Perspektiven der Forschung, Münster, LIT Verlag, pp. 151-186.

Parisse, Michel (2009), Les Chanoines réguliers. Émergence et expansion (XI ${ }^{e}$-XIII ${ }^{e}$ siècles), Saint-Étienne, Publications de l'Université de Saint-Étienne. 
Paxton, Jennifer (2002), Forging Communities: Memory and Identity in PostConquest England, "Haskins Society Journal" 10, pp. 95-109.

Peterson, David (2009), Reescribiendo el pasado. El Becerro Galicano como reconstrucción de la historia institucional de san Millán de la Cogolla, "Hispania" 69/233, pp. 653-682.

Quintana Prieto, Augusto (1971), Tumbo viejo de San Pedro de Montes, León, Centro de Estudios San Isidoro.

Rivera Recio, Juan Francisco (1962), El Arzobispo de Toledo, Don Bernardo de Cluny (1086-1124), Madrid - Roma, Iglesia Nacional Española.

Rivera Recio, Juan Francisco (1963), Privilegios reales y viejos documentos de Toledo, Madrid, Joyas bibliográficas.

Rivera Recio, Juan Francisco (1974), Patrimonio y señorío de Santa María de Toledo desde el 1086 hasta el 1208, "Anales Toledanos" 9, pp. 117-182.

Rodríguez Díaz, Elena E. (2011), Los cartularios en España. Problemas y perspectivas de investigación, en Rodríguez Díaz, Elena E.; García Martínez, Antonio Claret (eds.), La escritura de la memoria: los cartularios, Huelva, Universidad de Huelva, pp. 13-36.

Rodríguez Llopis, Miguel (1988), La escritura y el poder. La emisión de documentos en la sociedad murciana bajomedieval, "Áreas. Revista de Ciencias Sociales" 9, pp. 9-24.

Rucquoi, Adeline (1992), La invención de una memoria: los cabildos peninsulares del siglo XII, "Temas medievales" 2, pp. 67-80.

Sáez Sánchez, Carlos (1999), Documentos para ver, documentos para leer, “Anuario de Estudios Medievales" 29, pp. 899-916.

Sáez Sánchez, Carlos (2005), Origen y función de los cartularios: el ejemplo de España, "Gazette du livre médiéval" 46, pp. 12-21.

Sáez Sánchez, Carlos (2006), Orden, conservación y ostentación: el cartulario de la catedral de Sigüenza (c. 1212), "Anuario de Estudios Medievales" 36/1, pp. 171-199.

Sassenscheidt, Christian (2011), Mozarabes und Castellanos im Toledo des 12. Jahrhunderts: Die Entwicklung des Toledaner Doppelalcaldentums, en Maser, Matthias; Herbers, Klaus (eds.), Die Mozaraber: Definitionen und Perspektiven der Forschung, Münster, LIT Verlag, pp. 125-150.

Sutherland-Harris, Ronald (2012), Authority, Text, and Genre in Accounts of Diocesan Struggle: the Bishops of Bath and Glastonbury and the Uses of Cartulary Evidence, en Kanges, Sini; Korpiola, Mia; Tuija, Ainonen (eds.), Authorities in the Middle Ages: Influence, Legitimacy and Power in Medieval Society, Berlin - Boston, De Gruyter, pp. 107-123. 
Venturini, Alain (2009) Les cartulaires des anciens évêchés d'Uzes et de Nîmes, en Le Blévec, Daniel (ed.), Les cartulaires méridionaux. Actes du colloque organizé à Béziers, 20-21 septembre 2002, París, École Nationale des Chartes, pp. 21-32.

Vones-Liebenstein, Ursula (2009), L'expansion des chanoines réguliers dans la péninsule ibérique, en Parisse, Michel (ed.), Les Chanoines réguliers. Émergence et expansion (XI ${ }^{e}-X_{I I I}{ }^{e}$ siècles), Saint-Étienne, Publications de l'Université de Saint-Étienne, pp. 429-453.

Walker, David (1971), The organization of material in medieval cartularies, en Bullough, Donald; Storey, Robin L. (eds.), The Study of Medieval Records. Essays in honour of Kathleen Major, Oxford, Clarendon Press, pp. 206-235.

Zerner, Monique (2006), L'abbaye de Saint-Victor de Marseille et ses cartulaires: retour aux manuscrits, en Le Blévec, Daniel (ed.), Les cartulaires méridionaux. Actes du colloque organisé à Béziers, 20-21 septembre 2002, París, École Nationale des Chartes, pp. 163-216.

Fecha de recepción del artículo: junio 2015

Fecha de aceptación y versión final: marzo 2016 